\title{
EFSUMB Webinar CEUS
}

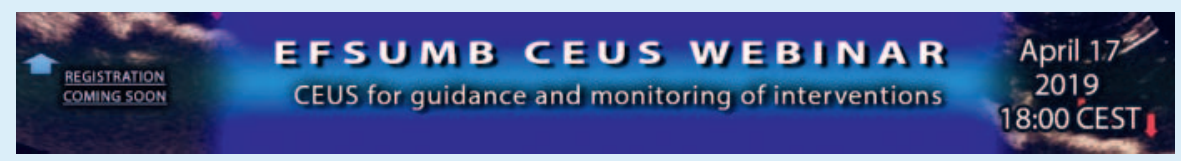

Chair Paul Sidhu

Percutaneous focal ablations

Luigi Solbiati

Transarterial chemoembolisation (TACE)

Ernst-Michael Jung

High-Intensity Focused Ultrasound (HIFU)

Prof. Cindy Angel

\section{EFSUMB Webinar Elastography Small Parts}

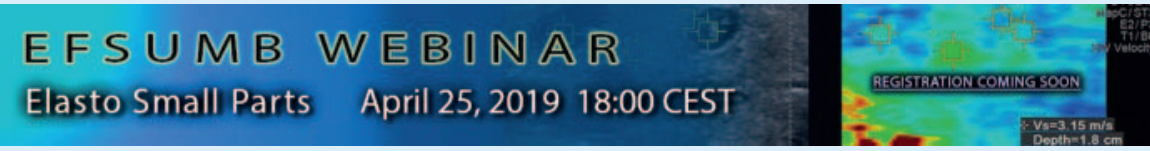

Pancreas \& Chair

Adrian Saftoiu

GI Track

Kim Nylund

Lymph Nodes

Christian Jenssen

Spleen

Horia Stefanescu

If you miss the webinars you can watch it on

the EFSUMB webinar archive

http://www.efsumb.org/blog/webinar-archive-2 